\title{
A POSSIBILIDADE DE NOVOS COMEÇOS ${ }^{1}$ Maria Cristina Müller (UEL) ${ }^{2}$ mcrismuller@hotmail.com
}

Resumo: Discute-se a capacidade humana de estabelecer novos começos no mundo. A pergunta que orienta a discussão refere-se à possibilidade da dignidade da política em tempos sombrios e em tempos de crise da democracia e do estado de direito. Parte-se do pressuposto de que a garantia da liberdade compõe o fundamento do Estado Democrático de Direitos, portanto a liberdade deve ser assegurada. No intuito de compreender a liberdade como pressuposto da democracia, objetiva-se elucidar a capacidade humana de trazer a novidade ao mundo, de começar, de iniciar. Para tal, utilizam-se como fundamentação teórica os estudos de Hannah Arendt acerca da atividade da ação - onde se faz imprescindível o discurso - e da capacidade de começar; a partir disso busca-se compreender a liberdade. A pesquisa é bibliográfica e utiliza como procedimentos a leitura, análise, compreensão e reconstrução teórica das reflexões de Hannah Arendt nas obras A condição humana, A vida do espirito, Da revolução, Origens do totalitarismo e Lições sobre a filosofia politica de Kant e nos textos Que é liberdade? e Que é autoridade?. Aponta-se que a dignidade da política encontra resposta na liberdade como o sentido da fundação das comunidades políticas e na possibilidade humana do estabelecimento de novos começos.

Palavras-chave: Começo; Ação; Liberdade; Política; Hannah Arendt.

\section{INTRODUÇÃO}

\section{A pergunta que orienta a discussão refere-se à possibilidade da dignidade da política em tempos sombrios e em tempos}

\footnotetext{
${ }^{1}$ Recebido em:25-10-2017/ Aprovado em: 28-03-2018/ Publicado on-line em: 07-08-2018.

${ }^{2}$ Maria Cristina Müller é Professora do Departamento de Filosofia da Universidade Estadual de Londrina, Londrina, PR, Brasil.
} 
de crise da democracia e do estado de direito. "Tempos sombrios" é uma expressão que Arendt utiliza no título do livro Homens em tempos sombrios, publicado em 1968. Neste livro ela apresenta reflexões e presta homenagens a várias personalidades - Gotthold Ephraim Lessing, Rosa Luxemburgo, Angelo Giuseppe Roncalli, Karl Jaspers, Isak Dinesen, Hermann Broch, Walter Benjamin, Bertolt Brecht, Walter Gurion e Randall Jarell -; homens e mulheres, que de algum modo viveram em tempos de escuridão; Arendt está preocupada em como viveram, como apareceram no mundo, e como foram afetadas pelo tempo histórico no qual viveram. A expressão, tempos sombrios, é tomada do poema de Brecht Aos que virão a nascer; para Arendt (1991, p. 21) os tempos sombrios são tempos nos quais o domínio público se obscurece e o mundo público se torna incerto; as pessoas deixam de ter fé e esperança no mundo público, espaço próprio da ação e da liberdade; o mundo público é desprezado e ignorado e as pessoas parecem contorná-lo, sem levá-lo em conta, para chegar a algum acordo. Tempos sombrios não são tempos de catástrofes, crimes e monstruosidades; tempos sombrios são os tempos em que o espaço público, o aparecer e o começar novas ações parecem sem sentido. No entanto, mesmo nestes tempos pode-se esperar que alguma luz seja lançada; luz que advém da ação, do dizer e da possibilidade de começar de alguns homens e mulheres que ousam aparecer no mundo público. Deste modo, as pessoas tratadas por Arendt no livro em questão são exemplares. Tempos de crise da democracia e do estado de direito são os tempos de hoje, não só no Brasil, mas no mundo; tempos em que a confiança na democracia e no estado de direito está fragilizada. Parte-se do pressuposto de 
que a garantia das liberdades, a ampla participação pública e a igualdade perante a lei compõem os fundamentos do estado democrático de direitos e que os Estados que se dizem democráticos deveriam proporcionar aos seus cidadãos meios de expressar suas singularidades. Deste modo, o cerceamento da liberdade e a eliminação dos espaços de aparecimento levam as democracias a não atenderem sua finalidade. No intuito de compreender a liberdade como pressuposto da democracia, objetiva-se elucidar a capacidade humana de trazer a novidade ao mundo, de começar, de iniciar. A liberdade, para Arendt, corresponde à espontaneidade, que, por sua vez, somente é possível e tem sentido quando o ser humano age no mundo; mundo constituído de uma pluralidade de seres humanos igualmente capazes de começar, isto é, de agir e discursar.

Hannah Arendt, na obra A condição humana, pergunta por aquilo que condiciona os seres humanos no mundo e apresenta as atividades do trabalho, da obra e da ação como pertencentes ao modo ativo da vida humana, ou seja, a dimensão da existência humana no mundo. Na obra A vida do espírito, trata das atividades que pertencem à dimensão da interioridade humana, isso é, ao modo contemplativo da vida humana, e elenca o pensar, o querer e o julgar como as atividades correspondentes a esse modo de vida. Entre todas as atividades humanas - trabalho, obra, ação, pensar, querer, julgar - a atividade da ação e a possibilidade humana de estabelecer novos começos interessam de modo especial à discussão proposta neste artigo. Deste modo, objetivase elucidar a capacidade humana de trazer a novidade ao mundo, de iniciar, de começar, o que, por sua vez, está li- 
gado à ideia de liberdade.

A noção de começo tem importância central para Hannah Arendt, perpassando vários de seus escritos. Ao penetrar no estudo acerca da capacidade humana de estabelecer novos começos, surgem conceitos que se interligam a este: ação, natalidade, pluralidade, espontaneidade e liberdade; deste modo, esses conceitos precisam ser igualmente tratados e elucidados. Na obra A condição humana, Arendt discute a ideia de começo ao apresentar a atividade da ação e nela o nascimento como um novo começo e ao apresentar a esperança e a fé como características primordiais da existência humana. No texto Que é autoridade?, a ideia de começo aparece como aspecto importante do caráter sagrado da fundação para os romanos, fundação como um novo começo. Exercendo um papel importante nos textos Que é liberdade? e Da revolução, a ideia de começo inspira o ato de fundação de uma nova comunidade política que, por sua vez, refuta a opressão pelo ato de liberação e pela esperança da liberdade como algo tangível. Na obra A vida do espírito, a noção de começo surge quando Arendt discute a atividade do querer e com ela a liberdade; contrapõe as ideias da liberdade filosófica enquanto exercício da vontade - euquero eu não-quero - revelador da singularidade, e da liberdade política enquanto poder - eu-posso - que só é possível no domínio da pluralidade, ou seja, no espaço do nós plural. Na obra A vida do espirito, Arendt analisa, como o fez na obra Da revolução, as narrativas lendárias das fundações das comunidades políticas que buscam a constituição do "nós" contido na ideia de "no princípio". Em ambas as discussões, Arendt invoca Agostinho de Hipona e o conceito 
de início, de começo, que acompanha o conceito de natalidade.

Para alcançar os objetivos propostos, o presente artigo é organizado em três partes: a primeira trata do ser humano como iniciador, a segunda aborda o começo contido nas narrativas lendárias das fundações das comunidades políticas e a terceira apresenta a tentativa dos governos totalitários de soterrar a dimensão da espontaneidade para dominar absolutamente o ser humano. A partir disso aponta-se que a dignidade da política encontra resposta na liberdade como o sentido da fundação das comunidades políticas e na possibilidade humana do estabelecimento de novos começos.

\section{O SER HUMANO COMO INICIADOR}

Arendt apresenta, na obra A condição humana, os seres humanos como iniciadores, como aqueles que tomam iniciativas e, assim, agem. É a natalidade, o fato de os seres humanos terem nascido e serem, deste modo, recémchegados em um mundo que existia antes deles, que os impele para a ação. A natalidade foi apresentada por Agostinho de Hipona quando ele asseverou que a criação do ser humano teria como propósito o começo; a vida propriamente humana não seria apenas resultado da multiplicação da espécie, mas deve-se ao fato de uma nova criatura aparecer em meio ao contínuo do tempo do mundo trazendo consigo a novidade, a possibilidade de iniciar o inaudito, o inimaginável. Os seres humanos continuamente agem no mundo em virtude de terem nascido; como seres nascentes, tomam iniciativas e realizam feitos, isto é, agem no mundo; agem 
para além das necessidades que a vida biológica impõe e da mera criação de objetos que possam ser úteis para suas vidas. A capacidade humana de começar algo novo no mundo a qualquer instante - agir - tem suas raízes na natalidade; a ação, como início, corresponde ao nascimento e à efetivação da condição humana da natalidade.

Há uma intrínseca conexão entre ação e início e a própria etimologia da palavra - agir - indica tal conexão. A palavra grega archeîn significa "começar", "ser o primeiro"; já o termo latino agere significa "imprimir movimento a alguma coisa", "fazer avançar", "conduzir"; assim, num sentido mais geral, agir significa "tomar iniciativa, iniciar". Portanto, "[...] é da natureza do início que se comece algo novo, algo que não se poderia esperar de coisa alguma que tenha ocorrido antes" (ARENDT 2010, p. 222).

O ser humano move-se para a ação porque é capaz de atos espontâneos. Espontaneidade não é sinônimo de impulsividade, mas diz respeito à capacidade de o ser humano começar algo novo no mundo, dar início a algo totalmente inédito. A espontaneidade, nesse sentido, está vinculada à natalidade, ao nascimento. Os seres humanos são seres recém-chegados a um mundo que os precede no tempo; por serem recém-chegados, trazem a novidade; há, por conseguinte, a liberdade - espontaneidade - como parte inseparável da condição humana. Nesse sentido, Arendt concorda com Kant quando ele diz que a liberdade é a "[...] faculdade [do homem] de começar espontaneamente uma série no tempo [...]" (ARENDT 1995, p. 267). Para Arendt (1995, p. 332), o dom da liberdade é o dom que cada ser humano possui no seu espírito para iniciar algo novo; algo que poderia não ter iniciado se assim decidisse; o dom é o de co- 
meçar, isto é, agir.

O ser humano nasce como indivíduo único e distinto, portanto singular; nasce em um mundo que existia antes dele, mundo composto por outros seres humanos igualmente únicos e distintos. Nasce dotado da capacidade de refletir por si mesmo - ao exercitar as atividades de pensar, querer e julgar - e de expor tal singularidade através do discurso. Como seres do mundo, homens e mulheres comunicam suas opiniões e pontos de vistas e, ao fazê-lo, agem no mundo. A ação só se revela pelo discurso. $\mathrm{O}$ discurso expõe, deste modo, tanto o resultado da reflexão, que é interna, quanto revela a ação, apresentando o "quem" do ser humano. Ao agir, ao tomar iniciativas e ao discursar, o ser humano expõe sua opinião diante dos demais e constrói, com isso, sua singularidade e identidade. Ao aparecer diante dos demais através da ação, que é acompanhada pelo discurso, o ser humano confirma sua identidade única, efetiva a realidade do próprio eu - singularidade - e do mundo circundante. A humanidade do ser humano está relacionada com esta capacidade de agir, com a espontaneidade possível na atividade da ação, com a capacidade de aparecer diante dos demais revelando a singularidade pela ação, pelo discurso.

A ação corresponde à condição humana da pluralidade, pois é a atividade exercida diretamente entre os homens sem a mediação das coisas - criações humanas - ou da natureza. Corresponde ao fato de que homens e mulheres, e não o Homem, vivem na Terra e habitam o mundo (ARENDT 2010, p. 8). Ação e discurso, ou atos e palavras, inserem o homem no mundo, distinguindo-o de todos os outros de sua espécie. Já que os homens se manifestam uns 
aos outros, não permanecem apenas diferentes, como meros objetos físicos, mas permitem-se aparecer como homens e mulheres singulares que são. Essa inserção do ser humano no mundo é um novo nascimento, depende da iniciativa, da espontaneidade, de cada um, não está ligada à necessidade, como no trabalho - labor -, nem à utilidade, como na fabricação; responde apenas ao ímpeto de iniciar algo novo.

A ação, para fim ilustrativo, está dividida em duas partes: o começo, feito por uma só pessoa, e a realização, que recebe a adesão de muitos para sua concretização. A ação acontece da relação com os outros seres humanos; necessita das palavras e dos atos dos demais, portanto, não pode acontecer no isolamento; a pluralidade é sua condição básica (ARENDT 2010, p. 219). A ação de um indivíduo se dá na teia de ações de muitos indivíduos e dela recebe reações que acontecem em cadeia, uma vez que a ação atua sobre seres também capazes de agir, ou seja, de realizar novas ações. Assim, a condição da pluralidade é compreendida, uma vez que é inegável a existência de indivíduos únicos e distintos, portanto, singulares que agem no mundo. $\mathrm{O}$ ser humano é singular e plural ao mesmo tempo. A pluralidade deriva do fato de que o ser humano não está só, de que existem homens e mulheres aos quais ação e discurso singular de cada um se dirigem. A pluralidade corresponde ao fato de os seres humanos necessitarem da presença constante de outros seres humanos que possam ver e ouvir seus atos, atestando, assim, a existência do outro.

Pode-se dizer que a capacidade humana da pluralidade faz com que os indivíduos sintam-se pertencentes à humanidade, coadjuvantes no mundo do qual também fazem 
parte, não permitindo que o sentimento de solidão os contamine. O sentimento de solidão, quando domina, destrói a capacidade humana de sentir-se pertencente a um mundo que agrega singularidade e pluralidade. A solidão é compreendida como a perda do próprio Eu, a perda da singularidade e da capacidade de refletir por si mesmo. A solidão é a "[...] experiência de não pertencer ao mundo, que é uma das mais radicais e desesperadas experiências que o homem pode ter" (ARENDT 1997, p. 527). Solidão é diferente de isolamento. $\mathrm{O}$ isolamento "[...] é aquele impasse no qual os homens se veem quando a esfera política de suas vidas, onde agem em conjunto na realização de um interesse comum, é destruída" (ARENDT 1997, p. 527). Ambos, solidão e isolamento, são destrutivos para a ideia de pertencimento e construção de um mundo comum. Arendt diz que Lutero já havia compreendido o problema da perda do próprio eu, característica da solidão, quando disse que: "[...] não é bom que os homens estejam sós [...] o homem solitário sempre pensa o pior de tudo [...]" (ARENDT 1997, p. 530).

Os seres humanos, no momento que perdem seu próprio Eu, perdem as garantias essenciais que o senso comum fornecia, isso é, garantias acerca de si mesmos - singularidade - e do mundo - pluralidade. Como saber se a experiência individual que cada um estabelece com o mundo e as sensações decorrentes dos cinco sentidos são reais se não existe um outro que possa atestar essa realidade? Nas palavras de Arendt:

[...] a própria faculdade do pensamento depende do seu uso público; sem o teste do exame livre e aberto, nenhum pensamento, nenhuma formação de opinião são possíveis. A razão não foi feita para 'isolar- 
se a si própria, mas para entrar em comunhão com os outros' [...]. Comunicabilidade implica uma comunidade de homens a quem se endereçar, os quais estão ouvindo e podem ser ouvidos [...]. Por que há homens (plural) e não o Homem? Kant responderia: a fim de que possam falar uns aos outros (ARENDT 1993, p. 53-4).

A dignidade humana transcende tudo o que o homem possa fazer ou produzir e concentra-se na capacidade de começar algo novo no mundo - espontaneidade, liberdade - que é dada na relação com o outro. Para Arendt (1997, p. 489), a degradação da espontaneidade transforma o indivíduo em fantoche facilmente manipulável, que concorda passivamente com tudo que lhe for ordenado; a eliminação da espontaneidade reduz o indivíduo a uma coisa. Esse, transformado em coisa, é incapaz de tomar qualquer posição e, consequentemente, de efetivar qualquer ação que advenha da reflexão e do julgamento dele próprio - sua única capacidade é a obediência cega.

[...] destruir a individualidade é destruir a espontaneidade, a capacidade do homem de iniciar algo novo com seus próprios recursos, algo que não possa ser explicado à base de reações ao ambiente e aos fatos. Morta a individualidade, nada resta senão horríveis marionetes com rostos de homem, todas com o mesmo comportamento do cão de Pavlov, todas reagindo com perfeita previsibilidade mesmo quando marcham para a morte (ARENDT 1997, p. 506).

No texto Que é liberdade?, Arendt (1992, p. 198) apresenta novamente a atividade da ação e explica que ela não está sob a direção do intelecto nem abaixo da vontade. Mesmo que a ação necessite de ambos - intelecto e vontade - o princípio da ação é incansável e inesgotável, pois pode se atualizar indefinidamente, pode ser repetido, pois é perene. Isto é possível porque a ação, na medida em que é livre, brota da capacidade de iniciar, de começar. Tal 
princípio da ação pode ser entendido como a honra, a glória, o amor à igualdade, o amor à distinção, a excelência, mas também o medo, a desconfiança, o ódio. Parece não importar muito o princípio, mas a possibilidade de agir - o ato em realização. "Os homens são livres - diferentemente de possuírem o dom da liberdade - enquanto agem, nem antes, nem depois; pois ser livre e agir são uma mesma coisa" (ARENDT 1992, p. 199).

A capacidade de ação dos seres humanos revela a capacidade do imprevisível, do improvável, do inesperado. O resultado da ação não pode ser previsto por duas razões: primeiro, porque cada ser humano, como único - singular -, pode empreender a novidade. $\mathrm{O}$ nascimento assegura um mundo singularmente novo para cada recém-chegado mesmo em meio a um mundo já existente. Segundo, porque o mundo existente é feito de outros seres igualmente capazes de agir e, portanto, de trazer novidade. Assim, jamais há certeza dos resultados da ação, sendo a imprevisibilidade dos resultados uma das características dela. Outra característica da ação é a irreversibilidade do processo. Tal irreversibilidade é entendida a partir da ideia de que toda ação como ato já efetivado - não pode ser revertida; não é possível desfazer aquilo que já foi realizado; vive-se e age-se no momento presente. Contrariamente à ação passada, que se apresenta como irremovível, a ação futura apresenta infinitas possibilidades. A rigidez intransponível do passado e a incerteza aterrorizante do futuro decorrentes da irreversibilidade e da imprevisibilidade da ação são contrapostas às faculdades de perdoar e prometer. Nas palavras da autora:

A redenção possível para a vicissitude da irreversibilidade - da inca- 
pacidade de se desfazer o que se fez, embora não se soubesse nem se pudesse saber o que se fazia - é a faculdade de perdoar. O remédio para a imprevisibilidade, para a caótica incerteza do futuro, está contido na faculdade de prometer e cumprir promessas. [...] perdoar, serve para desfazer os atos do passado [...] o obrigar-se através de promessas, serve para instaurar no futuro, que é por definição um oceano de incertezas, ilhas de segurança sem as quais nem mesmo a continuidade, sem falar na durabilidade de qualquer espécie, seria possível nas relações entre os homens (ARENDT 2010, p. 295).

Caso não existisse a faculdade de perdoar, a capacidade de ação estaria presa a um único ato, limitada às suas consequências. Se não existisse a faculdade da promessa, pela qual o ser humano obriga-se a cumprir o prometido, não haveria a conservação das identidades individuais. Para Arendt, (2010, p. 26), as faculdades da promessa e do perdão dependem diretamente da condição humana da pluralidade, visto que, no isolamento, essas faculdades não fazem sentido algum, não têm realidade.

Para Arendt, a ação e o discurso, bem como as possibilidades que o nascimento traz consigo, salvam os seres humanos de se verem reduzidos a processos vitais. Sem as faculdades de prometer e perdoar, os seres humanos estariam condenados a necessidades automáticas. A faculdade de agir interfere no ciclo da vida biológica, em que a mortalidade é uma lei segura, pois os seres humanos devem morrer, apesar de nascerem para começar, para iniciar algo novo. Neste sentido, segundo Arendt (2010, p. 308), o milagre que salva o domínio dos assuntos humanos da sua ruína inevitável é a natalidade. Portanto, as características essenciais da existência humana são a fé e a esperança; fé e esperança no mundo humano. Daí a importância da boanova do Evangelho: "nasceu uma criança entre nós". 
O código moral inferido por ambas as faculdades perdão e promessa - baseia-se na presença de outros seres humanos ao qual a promessa ou o perdão possa se dirigir. A desobrigação ou a disposição de mudar de ideia e recomeçar oferece aos seres humanos uma condição de liberdade para estabelecer novas relações. Os seres humanos não podem garantir hoje o que serão no amanhã, somente podem prometer; tampouco podem prever as consequências de um ato numa comunidade de outros seres capazes de agir, somente podem perdoar. $\mathrm{O}$ preço pago pela liberdade é a imprevisibilidade do futuro, parcialmente controlada pela faculdade de prometer. E o preço pago pela pluralidade é a impossibilidade de os atos humanos permanecerem absolutos e únicos.

As faculdades de perdoar e de prometer concedem à ação um mínimo de estabilidade e de solidez diante da fluidez da atividade da ação. Perdoar, segundo afirma Arendt na obra A condição humana, é a mais arriscada das ações humanas, pois tenta redimir aquilo que já foi feito e estabelecer um novo começo para aquilo que não pode ser desfeito. Sem a capacidade de perdoar, os seres humanos estariam presos a um único ato, do qual não poderiam se libertar. Sem o perdão não haveria novos começos. A capacidade de perdoar é a "[...] liberação, para que a vida possa continuar, desobrigando constantemente os homens daquilo que fizeram sem o saber [...]" (ARENDT 2010, p. 300). O perdão desobriga, libera da re-ação da ofensa inicial, por isso é o oposto da vingança, que mantém ofensor e ofendido ligados ao ato inicial da ofensa, portanto, impedidos de novos começos. 


\section{A NOÇÃO DE COMEÇO CONTIDA NAS NARRATIVAS DAS LENDAS FUNDADORAS}

Arendt também apresenta, nas obras $D a$ revolução e $A$ vida do espírito, a ideia de começo. Em Da revolução, Arendt (1990, p. 23) assevera que as ideias de começo e de liberdade são fundamentais para a compreensão das revoluções na Idade Moderna. Lembra Condorcet, que compreende que a própria palavra "revolucionário" somente poderia ser aplicada às revoluções que objetivavam a liberdade e que o nascimento da liberdade significava o início de uma nova História. $\mathrm{O}$ espírito revolucionário é a ânsia de libertar e de construir um lugar onde a liberdade pudesse habitar (ARENDT 1990, p. 28). Em A vida do espírito, Arendt apresenta novamente a ideia de fundação e assegura que a liberdade política somente se manifesta em comunidade, porque não é qualidade do indivíduo, mas do cidadão (ARENDT1995, p. 336); ela somente é possível no domínio do nós plural, no domínio da pluralidade humana. Esse nós existe onde quer que existam comunidades humanas.

A vida de um homem livre necessitava da presença de outros. Em consequência, a própria liberdade demandava um lugar onde as pessoas pudessem se reunir - a ágora, o mercado público, ou a polis, o espaço político propriamente dito (ARENDT 1990, p. 25).

A forma primeira deste nós é a família, que pode ser constituída de diferentes modos e transformar-se em diferentes formas de comunidades - formas de pluralidade humana. Apesar das diferentes comunidades, há algo em comum que pode ser observado como base de todas essas comunidades, isto é, o assentimento (ARENDT 1995, p. 
336), cujo modo mais natural é a obediência. Para que haja assentimento, há o reconhecimento de que nenhum ser humano pode agir sozinho, de que, se é pretensão realizar algo no mundo, isto deve ser realizado através de uma ação comum, através de um acordo.

Arendt chama a atenção para outro aspecto fundamental que está por trás deste nós, da pluralidade humana: por mais diversas que sejam as comunidades uma das outras, principalmente quanto ao aspecto de como se constitui esse nós, há uma aparência comum a todas elas, qual seja, sua gênese; todas as formas de pluralidade humana advieram de um grupo de pessoas que, em um dado momento e por alguma razão, pensaram sobre si mesmas como um nós; esse nós está ligado à capacidade de cada um começar, agir, iniciar.

O começo das comunidades humanas corresponde às narrativas lendárias de suas fundações. Por mais paradoxal que isso possa parecer, o fato é que, tanto no ocidente quanto no oriente, as lendas fundadoras foram imprescindíveis para auxiliar as gerações a compreenderem os mistérios que se encobrem nas gêneses na expressão "no princípio", que introduz tais narrativas. Essas narrativas se referiam não à criação divina, mas a um conjunto de ocorrências realizadas pelo ser humano no tempo humano que apresentam o marco da fundação da civilização. Arendt (1995, p. 338) explica que, mesmo que os seres humanos possam compreender a complexidade da grandeza do Universo, jamais serão capazes de conhecê-lo. Portanto, como tentativa de resolver o impasse - grandeza do universo e possibilidade de conhecê-lo -, apelam para as narrativas 
lendárias como forma de estabelecer um marco temporal o começo - em um tempo maior que não tem começo ou fim. O ser humano faz uso deste "no começo, no princípio" como um marco temporal que estabelece o início de algo em meio ao aparente caos. Em geral, a noção de começo apresenta-se hermética e talvez jamais se consiga alguma informação factual que esclareça definitivamente a significação contida na ideia de começo das lendas fundadoras. Apesar do mistério contido por detrás da expressão "no princípio", a ideia de começo, ou seja, a possibilidade de iniciar algo novo no contínuo do tempo, é que é importante.

Segundo Arendt (1995, p. 339), a civilização ocidental tem duas lendas fundadoras, a romana e a hebraica. Uma delas pode ser encontrada na narrativa bíblica do êxodo das tribos israelenses do Egito e a outra na narrativa de Virgílio - Eneida ${ }^{3}$ - sobre a peregrinação de Enéias que levou à fundação de Roma. Ambas iniciam com um ato de liberação, a fuga da opressão no Egito e a fuga de Tróia que, em chamas, estava preste a ser aniquilada. $\mathrm{O}$ ato de liberação é narrado da perspectiva de uma nova liberdade, isto é, a conquista de uma nova terra prometida e a fundação de uma nova Cidade ${ }^{4}$. As duas lendas são totalmente diferen-

\footnotetext{
${ }^{3}$ Obra inacabada de Virgílio, a qual, no leito de morte, ele teria pedido que fosse queimada. Refere-se à lenda do guerreiro Enéias, que, após a célebre guerra, teria fugido de Tróia, saqueada e incendiada, e chegado à Itália, onde se tornou o antepassado do povo romano. Epopeia erudita - o poema consta de doze livros - a Eneida tem como objetivo dar aos romanos uma ascendência não grega, formulando a cultura latina como original e não tributária da cultura helênica.

${ }^{4}$ Arendt (1995, p. 339) explica que a narrativa de Virgílio é uma inversão do exposto por Homero - na Ilíada. Na versão de Virgílio é Aquiles, na forma de Turno, quem foge e é morto por Heitor, na forma de Enéias. A fonte de toda a desgraça, novamente, é uma mulher, mas não mais uma adúltera - Helena para Homero - mas uma noiva - Lavínia; o fim da guerra não é pela vitória triunfante e pela destruição total dos derrotados, mas a vitória é consagrada a um novo corpo político - ambas as nações, invictas, entram num acordo e vivem sob a mesma lei para sempre.
} 
tes, mas apresentam um aspecto em comum, isto é, ambas surgiram de um povo "[...] que pensava em seu passado como uma história cujo começo era conhecido e podia ser datado [...]" (ARENDT 1995, p. 338). Os judeus sabiam o ano da criação do mundo, os romanos sabiam o ano da criação de Roma - 753 a.C. -, e ambos contam o tempo a partir destas datas. Para Arendt, no entanto, o que é mais impressionante é que, em ambas, o ato supremo - o princípio inspirador da ação - pelo qual o nós se constituiu foi o amor pela liberdade, "[...] a liberdade que advém de ser liberado e a liberdade que surge da espontaneidade de começar algo novo [...]" (ARENDT 1995, p. 338). Este amor pela liberdade inspirou o pensamento político ocidental.

As duas lendas fundadoras são muito distintas, mas inspiraram os homens de ação das Revoluções Francesa e Americana que buscavam na Antiguidade referências que pudessem guiar suas finalidades. Tal referência foi encontrada no "[...] hiatus entre o desastre e a salvação, entre a liberação da velha ordem e a nova liberdade, corporificada em um novus ordo seclorum, uma 'nova ordem das eras', com cujo nascimento o mundo se modificara estruturalmente" (ARENDT 1995, p. 339).

Para Arendt este hiato mostrava aos homens das Revoluções que a liberdade não seria um resultado natural da liberação, isto é, que o final do velho não significa necessariamente o surgimento do novo. Os homens de ação se depararam com a impossibilidade de um contínuo no tempo, descobriram que a sequência temporal toda poderosa é uma ilusão. Se pensar no tempo contínuo "normal", toda causa leva a um efeito correspondente e todo efeito 
necessariamente transforma-se imediatamente em uma causa de futuras ocorrências. Mas, no campo da ação, da atividade humana da ação, esta cadeia de causas e efeitos é quebrada com o ato de liberação, não restando nada a que aquele que iniciou a ação possa se agarrar. Arendt (1995, p. 341) explica que a liberação é conditio sine qua non da liberdade, mas a liberação não é a conditio per quam que causa a liberdade. Assim, o pensamento de um começo que se dá espontaneamente - sem causa e efeito - contido na narrativa de fundação, além de eliminar essa sequência de temporalidade elimina, pelo que se pode inferir, a noção de causa e efeito - típicas da cognição - como uma noção insuficiente para o campo da ação.

A narrativa da fundação, o "no princípio", a gênese, libera da opressão - é liberação - para daí se ter a possibilidade da liberdade, mas é apenas a possibilidade, não a garantia inequívoca da liberdade. $\mathrm{O}$ que a narrativa da fundação oferece é uma pausa, um hiato; ela depara com o abismo das infinitas possibilidades de escolhas e novos começos que, depois de feitos, não podem mais ser desfeitos. O que homens e mulheres farão diante desse abismo não é possível saber, isso é, não há certezas depois de se começar espontaneamente algo novo no mundo.

A filosofia sempre ficou um tanto perturbada com este poder de começar espontaneamente algo novo e o manterse ligada à sequência inquebrantável do contínuo do tempo, como se o começo fosse a continuação de uma série precedente. Para Arendt (1995, p. 339-340), a palavra revolução deveria resolver esse impasse. Nas últimas décadas do século XVIII, a palavra revolução deixou de se referir apenas à astronomia e passou a significar um acontecimento 
sem precedentes. Os Revolucionários tentaram "[...] superar o abismo entre o contínuo do tempo de sucessão ordenada e o começo de algo novo [...]" (ARENDT 1995, p.340), cada um a seu modo. Na França, instituíram um novo calendário - setembro de 1793 era o começo do Ano II - como um marco, como um novo começo, mas esta ideia fracassou e o novo calendário extinguiu-se em 1805. Arendt explica que, nos Estados Unidos da América, por mais tentadora que fosse a ideia de transformar o hiato da fundação da República norte-americana em um novo começo, eles sabiam que havia uma diferença muito grande entre liberação e liberdade e nunca utilizariam o hiato para explicar o que estavam fazendo. Eles eram colonizadores, respeitavam e se orgulhavam de ser ingleses; quando se rebelaram foi contra um governo injusto que os taxava excessivamente sem permitir a devida representação e, a partir disso, é que se sentiram habilitados a fundar um novo governo na terra dos homens livres. Segundo Arendt (1995, p. 343), quando os Pais Fundadores norte-americanos se conscientizaram de que o que estavam fazendo poderia se constituir em algo sem precedentes, um começo inteiramente novo, a novus ordum seclorum, recorreram aos antigos e a suas narrativas fundadores para buscar uma resposta ao problema do começo; recorreram principalmente às narrativas da fundação de Roma, em busca da prudência dos antigos que pudesse guiá-los nesta novidade que era a República, em que impera o governo das leis e não dos homens.

O que a revolução trouxe à luz foi essa experiência de ser livre e essa foi uma experiência nova, embora não na História do mundo ocidental - foi bastante comum na Antiguidade Greco-romana -, mas em relação aos séculos que 
separam a queda do Império Romano do advento da Idade Moderna. E essa experiência relativamente nova, pelo menos para aqueles que a viviam, foi, ao mesmo tempo, a experiência da capacidade do homem para iniciar alguma coisa nova. Essas duas coisas juntas - uma nova experiência que revela a capacidade do homem para a novidade - estão no pathos que encontramos tanto na Revolução Americana como na Francesa, esta sempre reiterada insistência de que nada comparável em grandeza e relevância jamais acontecera antes [...] (ARENDT 1990, p. 27).

Arendt observa que cada novo começo traz por natureza um elemento de arbitrariedade. Os Pais Fundadores norte-americanos queriam entender como resolver esse problema, eles precisavam resolver o problema da perplexidade inerente à tarefa da fundação. Neste momento, eles se depararam com o abismo da liberdade, isto é, tudo o que é feito poderia não ser feito, mas no momento que uma coisa é feita não pode mais ser desfeita e, além disto, a memória humana sobrevive ao arrependimento e à destruição. "[...] os atos e feitos que a libertação deles exigia, lançaram-nos na atividade pública, onde, intencionalmente ou muitas vezes inesperadamente, começaram a construir aquele espaço onde a liberdade pode revelar seus encantos [...]" (ARENDT 1990, p. 27). Outra questão se coloca, isto é, as lendas fundadoras apenas indicam o problema do começo como reiniciar o tempo dentro de um contínuo de tempo inflexível -, mas não o resolvem; assim, os Pais Fundadores norte-americanos tiveram que encontrar por eles mesmos uma solução. Eles já haviam compreendido que:

[...] um ato somente pode ser chamado de livre se não for afetado ou 
causado por alguma coisa que o precede, exigindo, ainda assim, à medida que se transforma imediatamente em uma causa do que quer que venha a se seguir, uma justificativa que, se vier a ter êxito, terá que apresentar o ato como a continuação de uma série precedente, isto é, virá a negar a própria experiência de liberdade e novidade (ARENDT 1995, p. 343).

O que precisava ser compreendido é que o ato de fundação não era totalmente novo, por isto é que, para Virgílio e para seus contemporâneos, a fundação de Roma não se deu com Rômulo, mas sim com Enéias. Enéias trouxe da Tróia destruída para a Itália Ilio junto com os Penates vencidos (ARENDT 1995, p. 344). O que precedera Roma foi o renascimento da Cidade-Estado de Tróia; Roma não surgiu simplesmente de um começo absoluto. A linha de continuidade e tradição fora preservada, o contínuo do tempo não fora quebrado, "[...] o grande ciclo de períodos nasce de novo [...]” (ARENDT1995, p. 344), como dizem os versos de Virgílio. Assim, a ordem das eras não é nova, mas um retorno a algo anterior. Deste modo, é possível compreender, de acordo com Arendt, o hino ao nascimento que Virgílio apresenta na Quarta Écloga ; para ele, a espécie humana se regenera constantemente, há novos nascimentos, há novas gerações, e essas podem trazer a salvação; talvez seja nisto que Virgílio acredita, conclui Arendt (1995, p. 345). O importante, contudo, segundo Arendt, é que os eventos das fundações, relembrados e preservados através da narração contar - do tempo, são restabelecimentos, reconstituições e não começos absolutos.

Arendt (1995, p. 346) expõe os motivos que a fizeram

${ }^{5}$ Écloga são poemas de Virgílio em número de dez; é o poema político mais famoso de Virgílio. 
analisar por algumas páginas os poemas de Virgílio ${ }^{6}$ : a) os primeiros passos dos seres humanos que viveram em um mundo secularizado foram guiados pelo saber da Antiguidade; b) as civilizações da Antiguidade foram marcadas por narrativas de fundação, que buscavam responder o "no princípio"; entre as narrativas mais significativas para a civilização ocidental está a da fundação de Roma; c) a análise do evento da fundação fez com que os homens de ação se confrontassem com o enigma da fundação - como reiniciar o tempo dentro de um contínuo de tempo inflexível; d) com a história da fundação de Roma de Virgílio, os homens de ação aprenderam que esta mesma fundação já era o renascer ou ressurgimento de Tróia, isto é, a própria primeira fundação já era o ressurgimento de um passado definido; e) disso aprenderam que fundar uma "nova Roma" era uma ilusão, mas eles deveriam repetir a história da fundação primitiva e fundar "Roma de novo"; f) tudo o que era anterior à primeira fundação situava-se fora da história, era natureza, cuja característica era possuir uma eternidade cíclica; a história, por sua vez, apresenta uma direção vertical e retilínea; g) a natureza poderia fornecer um refúgio para os homens de ação quando eles estivessem cansados dos negócios da cidadania, pois esta natureza não tinha preocupação alguma com a origem, a origem da natureza encontrava-se além da ação.

Arendt (1995, p. 347) mantém-se perplexa diante dos homens de ação das revoluções, pois, segundo sua análise,

${ }^{6} E$ É importante perceber que alguns pontos conclusivos que Arendt apresenta no resumo (1995, p. 346), na realidade, não foram analisados pela autora no decorrer do seu texto acerca dos poemas de Virgílio, mas infere-se que isto não é problemático, uma vez que os poemas apresentam um caráter mais ilustrativo do que propriamente reflexivo. 
eles não recorreram à Antiguidade na tentativa de inverter o eixo do tempo, isto é, fazer com que os jovens caminhassem de volta ao passado e a seu resplendor. Eles buscavam um paradigma, um exemplo, para sua era "esclarecida" e provavelmente não se davam conta de que estavam olhando para trás, tampouco se revoltaram contra essa Antiguidade quando perceberam que a resposta desta era que a salvação vinha do passado e que os ancestrais eram superiores. No texto Que é autoridade?, Arendt (1992, p. 163-164) explica que, do contexto da reflexão acerca do caráter sagrado da fundação, surge o conceito de autoridade. Autoridade auctoritas - deriva do verbo augere, que significa aumentar; aquilo que aqueles que têm posse da autoridade aumentam é a fundação. A autoridade tinha seu fundamento no passado, na ação, no ato, no começo estabelecido por aqueles que fundaram a cidade. Os revolucionários pensaram que haviam fundado um novo organismo político, a República, e desejavam, acima de qualquer outra coisa, iniciar uma nova ordem de coisa no mundo.

Outro problema percebido por Arendt é que os homens da Revolução - homens de ação - não perceberam a contradição entre a noção de futuro prenhe da salvação final que traz de volta uma Idade de Ouro e a ideia de Progresso - dominante na época - como conceito principal para a explicação do movimento da história.

Disto tudo o que interessa da análise de Arendt, nesse momento, é a frustração com a qual ela se depara. A autora explica que os homens de ação não puderam fornecer uma noção de liberdade destituída dos preconceitos advindos da noção equivocada de que a liberdade pertence apenas ao âmbito da interioridade - ao ego volitivo, que pode querer 
e não querer - e não ao âmbito da ação - em que homens e mulheres podem estabelecer espontaneamente novos começos, isso é, iniciar.

O abismo da pura espontaneidade - a possibilidade de fazer algo e de não fazê-lo, mas depois de feito não poder desfazer - que, nas lendas fundadoras, é superado pelo hiato entre liberação e a construção da liberdade, foi encoberto pela compreensão de que o novo é reafirmação do velho. A liberdade, na sua integridade original, somente sobreviveu, segundo Arendt (1995, p. 347), na teoria política como promessa utópica e infundada de um reino da liberdade.

Arendt (1995 p. 348) concebe, apesar dessa conclusão frustrante, encontrar em Agostinho de Hipona e na obra A cidade de Deus uma alternativa. A autora argumenta que o conceito de nascimento de Agostinho fornece a base para que a ação humana seja possível e a liberdade garantida. Segundo Agostinho explica na obra A cidade de Deus, Deus teria criado o homem como uma criatura temporal - tem um começo e um fim; como criatura nova que aparece em meio ao continuo do tempo do mundo. Tal criação teria como desígnio estabelecer um começo e a temporalidade seria afirmada por cada nova criatura - singular, única que nasce capaz de trazer a novidade, pois é capaz de iniciar algo novo no continuo do tempo. Agostinho (ARENDT 1995, p. 266) utiliza duas palavras para designar o começo do ser humano e o começo da criação: o homem foi criado no singular para que o initium - início - fosse feito; e esse início é diferente do principium da criação dos Céus e Terra. A partir disso, Arendt entende que o ser humano, por ser um começo, tem a possibilidade de querer ou não querer - 
faculdade da vontade - e que a liberdade da espontaneidade é parte da condição humana.

Arendt entende que os seres humanos estão destinados a serem livres porque nasceram, independentemente se lhes apraz ou não a arbitrariedade da liberdade. Homens e mulheres nasceram para iniciar, isso é, para agir, para estabelecer novos começos, para trazer ao mundo a novidade. A completa inação, a perda da possibilidade de atos espontâneos e, portanto, de liberdade, destitui homens e mulheres daquilo que são, ou seja, seres do mundo.

\section{A PERDA DA ESPONTANEIDADE HUMANA E OS TEMPOS SOMBRIOS}

A perda da espontaneidade só é possível em circunstâncias extraordinárias; um exemplo pode ser encontrado nos campos de concentração nazista. Sem espontaneidade, o que restou nos campos de concentração e extermínio na Alemanha Nazista foi algo como um outro espécime de animal humano; portanto, os campos demonstraram a possibilidade de manipulação da própria humanidade e dignidade dos seres humanos. Nos campos, a única coisa que se gestou foi a completa e profunda inação, submissão e aniquilamento da espontaneidade com o objetivo de destruir a personalidade humana - a dignidade humana.

[...] A experiência dos campos de concentração demonstra [...] que a 'natureza' do homem só é 'humana' na medida em que dá ao homem a possibilidade de tornar-se algo eminentemente não-natural, isto é, um homem (ARENDT 1997, p. 506).

O regime totalitário nazista percebeu cedo que o tipo 
de "coletividade" existente dentro dos campos de concentração e extermínio apresentava-se como a única forma de organização que permitiria dominar totalmente o ser humano e destruir qualquer possibilidade de contestação e, principalmente, de espontaneidade ${ }^{7}$, ambos frutos da singularidade. A atividade da ação, âmbito da espontaneidade, como explicado acima, vem acompanhada da imprevisibilidade, isto é, não há uma garantia absoluta do que cada indivíduo possa ou não fazer. Deste modo, a imprevisibilidade gera o tipo de comportamento inaceitável por um regime que pretende o domínio total. Assim, os campos de concentração e extermínio produzem (ARENDT 1997, p. 507) seres absolutamente desprovidas de qualquer espontaneidade e ação, seres totalmente indiferentes para com o mundo, deste modo, previsíveis e absolutamente manipuláveis.

[O ser humano] renuncia à liberdade de movimento quando se curva a uma tirania externa. A liberdade, como capacidade interior do homem, equivale à capacidade de começar, do mesmo modo que a liberdade como realidade política equivale a um espaço que permite o movimento entre os homens. [No totalitarismo] o terror é necessário para que o nascimento de cada novo ser humano não dê origem a um novo começo que imponha ao mundo a sua voz [...]. O governo totalitário só se sente seguro na medida em que pode mobilizar a própria força de vontade do homem para forçá-lo a mergulhar naquele gigantesco movimento da História ou da Natureza que supostamente usa a humanidade como material e ignora nascimento ou

\footnotetext{
${ }^{7}$ Conforme Arendt (1997, p. 506), o suicídio era algo raro nos campos de internamento nazista. É surpreendente perceber que, mesmo que existiam alguns mecanismos para prevenir a possibilidade de os internos cometerem suicídio, a dimensão da espontaneidade estava tão completamente aniquilada que esta alternativa era raramente cogitada e pretendida pelos internos. $\mathrm{O}$ ato do suicídio significaria a possibilidade de atos espontâneos e era isso que não poderia ser permitido; os internos haviam perdido a dimensão da espontaneidade com a morte da personalidade humana provocada pelo domínio total nazista.
} 
morte (ARENDT 1997, p. 525-26).

Convicções necessitam de liberdade e de pensamento reflexivo e crítico. $\mathrm{O}$ mundo totalitário não permite que os indivíduos exercitem sua capacidade de iniciar algo novo e de começar algo nunca realizado - ação -, nem propicia espaço para que cada indivíduo possa se movimentar e trocar suas convicções individuais com os demais. $\mathrm{O}$ totalitarismo necessita destruir qualquer possibilidade de vida pública. A eliminação do espaço da política, aquela dimensão que se estabelece entre os seres humanos quando eles agem em concerto, do domínio público do mundo, é um prérequisito para se estabelecer formas de governo totalitárias. Assim, o isolamento - a eliminação das relações sociais comuns e a não participação no domínio político - a que cada indivíduo se recolhe, traz como característica a impotência (ARENDT 1997, p. 526). Indivíduos isolados são impotentes, pois não conservam a disposição para a ação. Deste modo, deve-se estar alerta para a possibilidade de resistir a qualquer tipo de tirania, força esta que advém da capacidade humana de agir em conjunto e de estabelecer contatos no domínio público do mundo. Eliminados os espaços de contato político, elimina-se a capacidade humana para ação e, consequentemente, para a resistência a qualquer possibilidade de dominação.

\section{CONSIDERAÇÕES FINAIS}

Arendt (1992, p. 185) considera que a crise do mundo (século XX) é claramente de caráter político. A descrença na política, como o espaço entre-os-homens, acompanha a his- 
tória do ocidente desde Platão e culmina na contemporaneidade com o desinteresse e o preconceito da maioria para com as questões que dizem respeito ao mundo comum. Há um voltar-se para o domínio privado das vidas e o ser humano passa apenas a se comportar, não mais a agir. Para Arendt o "declínio do Ocidente" consiste no declínio da trindade romana - religião, tradição, autoridade - e o concomitante minar do domínio político firmado nas fundações romanas.

A partir do exposto, a dignidade da política em tempos sombrios e em tempos de crise da democracia e do estado de direito encontra resposta na ideia da liberdade como o sentido da fundação das comunidades políticas e na possibilidade humana do estabelecimento de novos começos. A dignidade da política, em tempos como os vividos pela humanidade hoje, somente pode ser encontrada se não houver o esquecimento que o ser humano ama a liberdade, ama-a por que é um iniciador e, por sê-lo, traz a novidade.

Supõe-se, portanto, que é este espírito que deve ser galgado. A prevalência de homens e mulheres que amam a liberdade e, por amá-la respeitam, a pluralidade humana, deve ser o guia a orientar os caminhos nestes tempos de crise. A generosidade de saber ouvir a todos, de encontrar no discurso do outro um sentido e revelar este sentido na cuidadosa palavra dirigida a esse outro, deve ser preservada. $O$ ser humano é iniciador, pode começar algo novo no mundo e esta possibilidade não the pode ser roubada. O ser humano pode instituir organismos políticos que preservem o espaço próprio do ser humano, o espaço da ação e do discurso, o espaço público do mundo. Deste modo, ao aparecer em atos e palavras, ao começar, cada homem e mulher 
poderão iluminar os tempos sombrios.

Abstract: The human capacity to establish new beginnings in the world is discussed. The question that guides the discussion refers to the possibility of the dignity of politics in dark times and in times of crisis of democracy and the rule of law. It is based on the assumption that the guarantee of freedom is the basis of the Democratic State of Rights, so freedom must be guaranteed. In order to understand freedom as a presupposition of democracy, it aims to elucidate the human capacity to bring novelty to the world, to begin, to start. To this end, Hannah Arendt's studies on the activity of action where the discourse becomes essential - and the ability to begin are used as the theoretical foundation; from this it is sought to understand freedom. The research is bibliographical and uses as a procedure the reading, analysis, comprehension and theoretical reconstruction of the reflections of Hannah Arendt in the works The human condition, The life of the spirit, Of the revolution, Origins of totalitarianism and Lessons on the political philosophy of Kant and in the texts What is freedom? And what is authority? It is pointed out that the dignity of politics finds its answer in freedom as the sense of the foundation of political communities and in the human possibility of establishing new beginnings.

Keywords: Beginning; Action; Freedom; Policy; Hannah Arendt.

\section{REFERÊNCIAS}

ARENDT, Hannah. A condição humana. 11. ed. Tradução de Roberto Raposo. Revisão e Apresentação de Adriano Correia. Rio de Janeiro: Forense Universitária, 2010.

. Origens do totalitarismo: anti-semitismo, imperialismo, totalitarismo. Trad. Roberto Raposo. São Paulo: Companhia das Letras, 1997.

- A vida do espírito: o pensar, o querer, o julgar. 3. ed. Trad. Antonio Abranches; César Augusto R. de Almeida; Helena Martins. Rio de Janeiro: Relume-Dumará, 1995.

Lições sobre a filosofia política de Kant. Trad. André Duarte de Macedo. Rio de Janeiro: Relume-Dumará, 
1993.

. Entre o passado e o futuro.3. ed. Trad. Mauro W. Barbosa de Almeida. São Paulo: Editora Perspectiva, 1992.

. Homens em tempos sombrios. Tradução de Ana Luísa Faria. Lisboa: Relógio D’Água, 1991.

. Da revolução.2. ed. Trad. Fernando Dídimo Vieira. São Paulo/Brasília: Editora Ática/ Editora Universidade de Brasília, 1990. 